\title{
Graft Copolymerization of Methyl Acrylamide onto Jute Fibers Initiated by Peroxydisulfate Catalyzed by Fe(III)
}

\author{
Rajani K. SAMAL, ${ }^{*}$ Sabyasachi DASH, and Atish K. SWAIN \\ Makromolecular Research Laboratory, Department of Chemistry, \\ Ravenshaw College, Cuttack-753003, Orissa, India
}

(Received August 31, 1988)

\begin{abstract}
Graft copolymerization of methyl acrylamide [MAM] onto jute fiber has been studied in an aqueous medium using potassium persulfate as an initiator, under the catalytic influence of $\mathrm{FeCl}_{3}$ in nitrogen atmosphere. Grafting is influenced by reaction time, temperature, concentration of monomer, initiator, catalyst, and base polymer. For comparative catalytic influence the reaction has also been carried out in presence of various salts and organic solvents. The maximum graft percent of 70.6 is obtained at $50^{\circ} \mathrm{C}$ for the following concentrations; monomer $(0.8 \mathrm{M}), \mathrm{K}_{2} \mathrm{~S}_{2} \mathrm{O}_{8}(0.03 \mathrm{M})$, catalyst $\mathrm{Fe}(\mathrm{III})\left(1.5 \times 10^{-3} \mathrm{M}\right)$ and composition of acetic and formic acid of $2.5 \%(\mathrm{v} / \mathrm{v})$. From the experimental results a mechanism for graft initiation and termination has been suggested. The extent of absorption of water and water vapors, the tensile properties and thermal behavior of the grafts have also been tested.

KEY WORDS Graft Copolymerization / Methyl Acrylamide / Jute Fiber / Potassium Persulfate $/ \mathrm{FeCl}_{3} /$ Tensile Modulus / Primary Thermogram /
\end{abstract}

Graft copolymerization of vinyl monomers onto cellulose, lignocellulose and their derivatives has been the subject of extensive studies since $1946 .{ }^{1}$ Graft copolymerization of preformed polymers both natural and synthetic provides a potential route for significantly altering their physical and mechanical properties. The grafting possesses great potential for tailoring material properties to specific end use. Jute, a lignocellulosic polymer, is the most abundant renewable agricultural raw material. It is transformed into multiferious products due to its wide application for making coarse woven fabrics such as gunny sacks and bagging where the cheapness is the essential factor. Recently efforts are being made in India and Bangladesh for commercial utilization of jute fibers to meet the total fabric requirements of the country as well as to minimize the import of synthetic fibers. Although jute fiber possesses high dimensional stability, certain unfavorable textile properties like high stiffness, very low elasticity, susceptibility towards sun light, etc. they have tremendously limited for their use. ${ }^{2}$ Therefore, to minimize the undesirableness for intensified textile uses, graft copolymerization of some vinyl monomers onto jute fibers has been attempted during the recent years using chemical, photo chemical, and radiation induced methods of initiation. ${ }^{3-14}$ Among all these reports encouraging results have been obtained by Mehta et $a l^{4,5}$ where the grafted fibers showed improved tenacity, dyability and tensile properties while rest of the reports are not so much convincing. Further among the methods of initiation, chemical methods of initiation of grafting involving oxidizers like

\footnotetext{
* To whom all correspondence are to be addressed.
} 
$\mathrm{Ce}(\mathrm{IV}), \mathrm{V}(\mathrm{V}), \mathrm{Mn}(\mathrm{VII}), \mathrm{K}_{2} \mathrm{~S}_{2} \mathrm{O}_{8}, \mathrm{KHSO}_{5}$ etc. are promising from the economic and industrial point of view and are quite selective in nature. Among the chemical initiators persulfate ion $\left(\mathrm{S}_{2} \mathrm{O}_{8}^{2-}\right)$ has a separate identity of its own. Persulfate ion is known to act as a strong oxidizing agent in an aqueous solution, and either alone or in the presence of an activator has been used as an initiator of vinyl polymerization. ${ }^{15-22}$ However the use of persulfate redox system for initiation of graft copolymerization of vinyl monomers onto cellulosic substrates was recognised in 1963. Since then persulfate ion alone or with suitable catalyst has been used for initiating graft copolymerization onto various cellulosic substrates. ${ }^{13,23-33}$ The present report describes graft copolymerization of methyl acrylamide [MAM] onto jute fibers initiated by $\mathrm{K}_{2} \mathrm{~S}_{2} \mathrm{O}_{8} /$ $\mathrm{Fe}(\mathrm{III})$ couple and the effect of percent grafting on the properties of the grafts.

\section{EXPERIMENTAL}

\section{Materials}

Jute fibers (Corchoru capsularis) were purified by repeated Soxhelation with a mixture of ethanol and benzene $(1: 2$ by $\mathrm{v} / \mathrm{v})$ followed by washing with cold ethanol and air dried. Methyl acrylamide (MAM) was purified by recrystallization from acetone. A stock solution (4 M) of the monomer was used for the grafting reaction. A stock solution of the initiator " $\mathrm{K}_{2} \mathrm{~S}_{2} \mathrm{O}_{8}$ " ( $(0.1 \mathrm{M})$ was prepared by dissolving $10.81 \mathrm{~g}$ of the salt (E. Merck) in triple distilled water. The activity of stock solution was determined by cerimetry. All other reagents were used after purification by standard methods.

Graft copolymerization was carried out in a specially designed reaction vessel carrying outlet and inlet systems, for deaeration. The defatted jute fibers $(0.2-1.0 \mathrm{~g})$ were immersed in a mixture containing water, required amount of MAM and ferric chloride. The reaction vessels were deaerated by passing oxygen-free nitrogen gas for one hour and were then sealed airtight by rubber capping. The vessels were than kept in a continuous shaking thermosttated bath, till the mixtures attained thermal equilibrium after which required amount of the initiator was injected through the rubber capping. The reaction was carried out for the desired time. The homopolymers were extracted by repeated boiling of the grafts in distilled water till washings did not yield any precipitate with methanol.

From the weight of the grafts and parent fiber, the percent grafting was calculated as follows:

$$
\text { Percent grafting }=\frac{X-Y}{Y} \times 100
$$

where $X$ and $Y$ was weight of the graft copolymer, and that of the original base polymer, respectively.

\section{MECHANISM}

The mechanism of graft copolymerization may be pictured as involving generation of macro-jute radicals resulting from the attack of the primary radicals $\mathrm{SO}_{4}^{-}$and $\mathrm{Cl}^{-}$produced from the initiator either alone or under the catalytic influence of $\mathrm{FeCl}_{3}$ at the jute backbone. Further the macro-jute radical formation may be caused by $\mathrm{HO}^{\circ}$ radicals produced from the oxidation of $\mathrm{H}_{2} \mathrm{O}$ by $\mathrm{SO}_{4}^{-} \cdot{ }^{34}$ Attack of the resulting jute radicals on the monomer molecules at the immediate vicinity results in graft initiation. Homopolymerization of methyl acrylamide and oxidation of jute radicals through primary radical initiation may also take place as side reactions.

\section{Primary Radical Production}

$$
\begin{aligned}
& \text { (i) } \mathrm{S}_{2} \mathrm{O}_{8}^{2-} \frac{k_{\mathrm{d}}}{\text { Thermal }} \\
& \text { (ii) } \mathrm{S}_{2} \mathrm{SO}_{8}^{2-}+\mathrm{FeCl}_{3}^{-} \stackrel{k_{\mathrm{d}}^{\prime}}{\longrightarrow} \\
& \qquad \mathrm{SO}_{4}^{-\cdot}+\mathrm{SO}_{4}^{2-}+\mathrm{Cl}^{-}+\mathrm{FeCl}_{2}
\end{aligned}
$$

(iii) $\mathrm{SO}_{4}^{-}+\mathrm{H}_{2} \mathrm{O} \stackrel{k_{\mathrm{o}}}{\longrightarrow} \mathrm{SO}_{4}^{2-}+\mathrm{HO}^{\cdot}+\mathrm{H}^{+}$ 
Step (ii) of primary radical production seems to be true, as has been verified from the liberation of $\mathrm{Cl}_{2}$ which may result from the coupling of two $\mathrm{Cl}^{\circ}$ radicals $\mathrm{Cl}^{\circ}+\mathrm{Cl}^{\circ} \longrightarrow \mathrm{Cl}_{2}$

2. Formation of Macrojute Radical

$$
\begin{aligned}
\mathrm{J}-\mathrm{H}+\mathrm{R}^{\cdot} \stackrel{k_{\mathrm{r}}}{\longrightarrow} & \mathrm{J}^{\cdot}+\mathrm{R}-\mathrm{H} \\
& \left(\mathrm{R}^{\cdot}=\mathrm{SO}_{4}^{-}, \mathrm{HO}^{\circ}, \text { and } \mathrm{Cl}^{\circ}\right)
\end{aligned}
$$

3. Graft Initiation

$$
\mathbf{J}+\mathbf{M} \stackrel{k_{\mathbf{i}}}{\longrightarrow} \mathbf{J}-\mathbf{M}^{\cdot}
$$

4. Non-Graft Initiation

5. Propagation

$$
\mathrm{R}^{\cdot}+\mathrm{M} \stackrel{k_{\mathrm{i}}^{\prime}}{\longrightarrow} \mathrm{R}-\mathrm{M}^{\cdot}
$$

(a) Grafting:

$$
\begin{gathered}
\mathrm{J}-\mathrm{M}^{\cdot}+\mathrm{M} \stackrel{k_{\mathrm{p}}}{\longrightarrow} \mathrm{J}-\mathrm{M}_{2}^{\cdot} \\
\vdots \\
\mathrm{J}-\mathrm{M}_{n-1}^{\cdot}+\mathrm{M} \longrightarrow \mathrm{J}-\mathrm{M}_{n}^{\circ}
\end{gathered}
$$

(b) Homopolymerization:

$$
\begin{gathered}
\mathrm{R}-\mathrm{M}^{\cdot}+\mathrm{M} \longrightarrow \mathrm{R}-\mathrm{M}_{2} \\
\vdots \\
\mathrm{R}-\mathrm{M}_{m-1}^{\cdot}+\mathrm{M} \longrightarrow \mathrm{R}-\mathrm{M}_{m}^{\circ}
\end{gathered}
$$

6. Termination of Grafting

(i) $\mathbf{J}-\mathbf{M}_{n}^{\cdot}+\mathbf{J}-\mathbf{M}_{n}^{*}$

$\longrightarrow$ Cross-linked polymer

(ii) $\mathrm{J}-\mathrm{M}_{n}^{\cdot}+\mathrm{Fe}(\mathrm{III})$

$\longrightarrow$ Graft copolymer $+\mathrm{Fe}(\mathrm{II})+\mathrm{H}^{+}$

(iii) $\mathrm{J}-\mathrm{M}_{n}^{\cdot}+\mathrm{R}^{\cdot} \longrightarrow \mathrm{J}-\mathrm{M}_{n}-\mathrm{R}$

7. Oxidation

$\mathbf{J}^{\cdot}+\mathrm{SO}_{4}^{-\cdot} \stackrel{k_{\mathrm{o}}^{\prime}}{\longrightarrow}$ Oxidation products

\section{RESULTS AND DISCUSSION}

Methyl acrylamide [MAM] was graft copolymerized onto defatted jute fibers using $\mathrm{K}_{2} \mathrm{~S}_{2} \mathrm{O}_{8}$ as an initiator either alone or in the presence of a number of salts as catalyst. The

\begin{tabular}{|c|c|}
\hline Salts & Grafting $\%$ \\
\hline No salt & 1.1 \\
\hline $\mathrm{FeCl}_{3}$ & 11.7 \\
\hline $\mathrm{Fe}_{2}\left(\mathrm{SO}_{4}\right)_{3}$ & 7.2 \\
\hline $\mathrm{CuSO}_{4}$ & 4.8 \\
\hline $\mathrm{NaBr}$ & 2.3 \\
\hline $\mathrm{ZnSO}_{4}$ & 3.3 \\
\hline $\mathrm{K}_{2} \mathrm{SO}_{4}$ & 2.2 \\
\hline $\mathrm{CdCl}_{2}$ & 5.8 \\
\hline $\mathrm{CoSO}_{4}$ & 4.8 \\
\hline $\mathrm{Cr}_{2}\left(\mathrm{SO}_{4}\right)_{3}$ & 8.2 \\
\hline $\mathrm{MgSO}_{4}$ & 4.4 \\
\hline $\mathrm{MnSO}_{4}$ & 1.3 \\
\hline $\mathrm{NiSO}_{4}$ & 4.9 \\
\hline $\mathrm{AgNO}_{3}$ & 1.1 \\
\hline $\mathrm{FeSO}_{4}$ & 10.3 \\
\hline $\mathrm{Na}_{2} \mathrm{~S}_{2} \mathrm{O}_{3}$ & 0 \\
\hline
\end{tabular}
results of percent grafting for the individual systems are presented in Table I.

From the results in Table I, it is observed that the presence of all the salts except $\mathrm{AgNO}_{3}$
Table I. Graft percent in $\mathrm{K}_{2} \mathrm{~S}_{2} \mathrm{O}_{8}$ initiated graft copolymerization of MAM onto jute fiber under the influence of various salts

and $\mathrm{Na}_{2} \mathrm{~S}_{2} \mathrm{O}_{3}$ enhance the percent grafting. The enhancement of percent grafting in the presence of these salts and increasing trend as cited above may be attributed to the progressive increase in the rate of decomposition of $\mathrm{K}_{2} \mathrm{~S}_{2} \mathrm{O}_{8}$ to massive free radicals $\left(\mathrm{SO}_{4}^{-}\right)$. They attack the jute backbone resulting in the formation of a number of free radical sites, then the monomer addition takes place on it. The complete inhibition of grafting in the presence of $\mathrm{Na}_{2} \mathrm{~S}_{2} \mathrm{O}_{3}$ may be due to the deactivation of the initiator through oxidative disproportionation of the latter.

\section{(i) Effect of Monomer Concentration}

Graft copolymerization of MAM onto jute fibers has been studied with different monomer concentration. The percent grafting increases with increase of monomer concentration upto $0.9 \mathrm{M}$, beyond which it decreases (Figure 1). The enhancement of percent grafting in this case may be interpreted in terms of increase in the concentration of MAM at the reaction site and complexation of jute with MAM enhanc- 


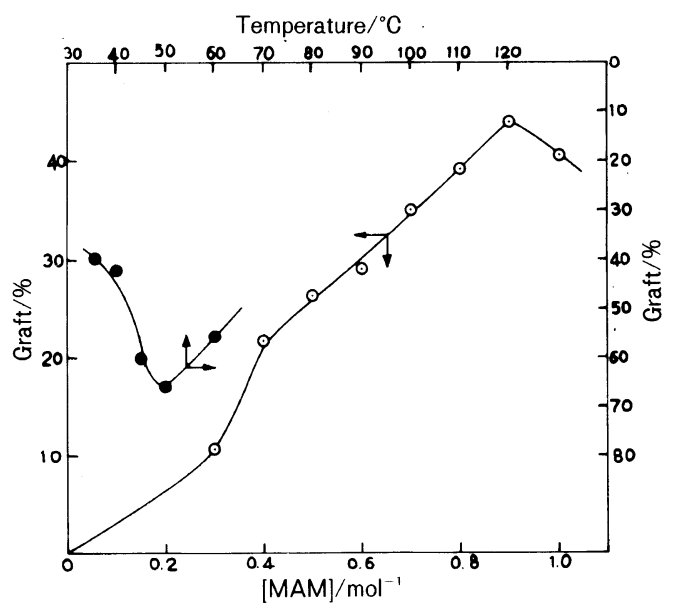

Figure 1. Effect of monomer concentration $(\odot)$ and temperature (O) on the graft percent: Jute $=0.2 \mathrm{~g}$; $\left[\mathrm{K}_{2} \mathrm{~S}_{2} \mathrm{O}_{8}\right]=0.01 \mathrm{M}(\odot)$ and $0.03 \mathrm{M}(\odot) ;\left[\mathrm{FeCl}_{3}\right]=$ $1.5 \times 10^{-3} \mathrm{M}$; [MAM] $=0.8 \mathrm{M}(\odot)$ at $45^{\circ} \mathrm{C}(\odot)$ fro $6 \mathrm{~h}$.

ing of reactivity owing to the formation of a donor-acceptor complex. Similar explanations for enhancement in grafting with increase in monomer concentration have been presented by Gaylord, ${ }^{35}$ Hebeish et al. ${ }^{36}$, and Samal et al. $^{37}$

The decrease of percent grafting beyond the monomer concentration of 0.9 may be attributed to agglomeration of the fibers as well as poly(methyl acrylamide) PMAM homopolymers resulting in the formation of lumps thereby decreasing the number of free radical surface sites available for monomer addition. Similar explanation for the decrease of percent grafting at high monomer concentration has been observed by Hon et al. ${ }^{38}$

\section{(ii) Effect of Initiator Concentration}

The graft copolymerization was studied at various initiator concentrations $\left(5 \times 10^{-3}\right.$ $\left.35 \times 10^{-3} \mathrm{M}\right)$ at fixed concentration of MAM $(0.8 \mathrm{M}) .\left[\mathrm{FeCl}_{3}\right]\left(1.5 \times 10^{-3} \mathrm{M}\right)$ at $45^{\circ} \mathrm{C}$ for a reaction time of $6 \mathrm{~h}$. The percent grafting increased with increase in the initiator concentration upto $3 \times 10^{-2} \mathrm{M}$ and reached a constant value (Figure 2). The increase may be attributed to increase in the number of active

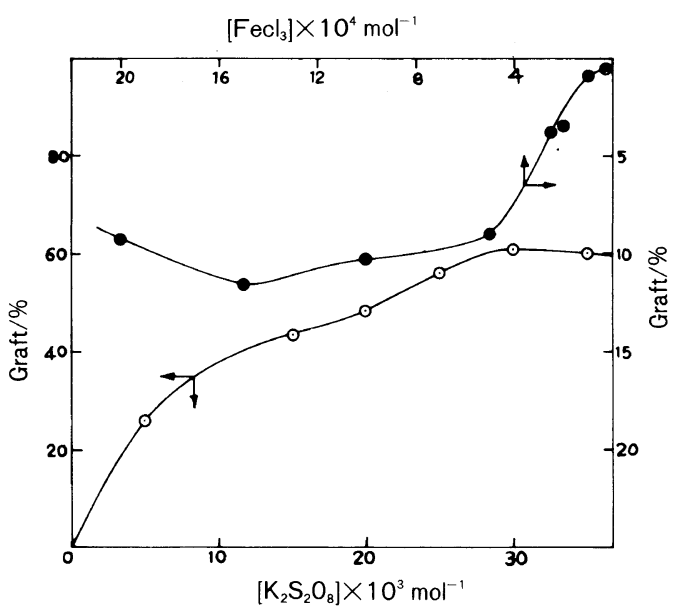

Figure 2. Effect of initiator concentration $(\odot)$ and $\mathrm{FeCl}_{3}$ concentration (O) on the graft percent: $\left[\mathrm{K}_{2} \mathrm{~S}_{2} \mathrm{O}_{8}\right]=0.01 \mathrm{M}$ (O): Jute $=0.2 \mathrm{~g} ; \quad[\mathrm{MAM}]=0.8 \mathrm{M}$ $(\odot)$ or $0.2 \mathrm{M}(\odot) ;\left[\mathrm{FeCl}_{3}\right]=1.5 \times 10^{-3} \mathrm{M}(\odot)$ at $45^{\circ} \mathrm{C}$ for $6 \mathrm{~h}$.

sites on the backbone of jute fibers. Graft initiation by free radical sites both at and below the surface region of the fibers positively contributes to enhancement of the grafting. The stagnation of graft percentage beyond $\left[\mathrm{K}_{2} \mathrm{~S}_{2} \mathrm{O}_{8}\right]$ of $30 \times 10^{-3} \mathrm{M}$ may be attributed to (i) homopolymerization by excess of primary radicals formed from the initiator and (ii) the other factor due to premature termination of the growing grafted chains by excess of primary radicals.

\section{(iii) Effect of Catalyst Concentration}

Graft copolymerization has been studied at different $\mathrm{FeCl}_{3}$ concentrations. It has been observed that the percent grafting increases on increasing the concentration of $\mathrm{FeCl}_{3}$ upto $1.5 \times 10^{-3} \mathrm{M}$ and then decreases (Figure 2). The enhancement of percent grafting may be attributed to forced decomposition of $\mathrm{K}_{2} \mathrm{~S}_{2} \mathrm{O}_{8}$ in a transition state on interaction with excess of $\mathrm{Fe}$ (III) leading to the production of primary radicals on the fiber surface which immediately attacks it's backbone resulting in the creation of a large number of free radicals. The decrease in percent grafting at higher 
concentration of $\mathrm{FeCl}_{3}$ may be attributed to the detrimental factor of excess of $\mathrm{Fe}(\mathrm{III})$ ions leading to retardation of rate through premature termination of the growing grafted chains. That has been reported by Rogovin et al. ${ }^{39}$ and Mishra et al. ${ }^{40}$

\section{(iv) Effect of Temperature}

The effect of temperature on percent grafting is shown in Figure 1. It has been observed that the percent grafting increases upto $50^{\circ} \mathrm{C}$ and then decreases. The increase can be explained by (i) increase in the production rate of active free radicals which increase the number of grafting sites at a greater rate thereby the rate of graft initiation increases and (ii) increase in the rate of diffusion of MAM into the fiber matrix where grafting is also initiated. Samal and co-workers ${ }^{41-43}$ have identical observations in the grafting of acrylamide onto Nylon-6, silk fiber and cellulose, respectively.

The decrease in the percent grafting beyond $50^{\circ} \mathrm{C}$ may be ascribed to (i) activation of jute backbone and the initiator leading to overall oxidation of the former, (ii) increase in the rate of production of homopolymers, (iii) premature termination of growing grafted chains by $\mathrm{Fe}$ (III) and (iv) ion premature termination of growing polymer chains by transition metal ions in their higher valence state which has been observed by Bamford et al. ${ }^{44}$ and Samal et al. ${ }^{45}$

\section{(v) Effect of Organic Solvents}

The effect of organic solvents on the graft percent has been studied. The results are presented in Table II.

The presence of acetic acid and formic acid of $2.5 \%$ to $5 \%(\mathrm{v} / \mathrm{v})$ in the reaction mixture enhances grafting, and beyond $5 \%$ there is progressive decrease in the graft percentage. However at $5 \%$ of the solvents the percent grafting is less than that at $2.5 \%$. Further it is also noticed that with rest of the solvents a progressive decrease in the percent grafting from the control value is noticed right from
Table II. Variation of percent grafting at fixed time effect of various solvent composition

\begin{tabular}{rrrrrr}
\hline [Solvent] & \multicolumn{5}{c}{ Graft percent } \\
\cline { 1 - 4 } $\mathrm{v} / \mathrm{v}$ & Pyridine & Acetone Methanol & $\begin{array}{c}\text { Acetic } \\
\text { acid }\end{array}$ & $\begin{array}{c}\text { Formic } \\
\text { acid }\end{array}$ \\
\hline $2.5 \%$ & 36.7 & 57.0 & 60.7 & 70.7 & 70.1 \\
$5.0 \%$ & 32.2 & 56.6 & 60.4 & 68.2 & 68.0 \\
$7.5 \%$ & 26.4 & 56.0 & 57.6 & 68.1 & 60.6 \\
$10.0 \%$ & 26.2 & 54.6 & 56.5 & 62.5 & 48.1 \\
$12.5 \%$ & 23.3 & 54.0 & 54.6 & 55.0 & 47.6 \\
$15.0 \%$ & 14.8 & 49.5 & 44.5 & 49.5 & 51.4 \\
\hline
\end{tabular}

Jute $=0.2 \mathrm{~g} ; \quad[\mathrm{MAM}]=0.8 \mathrm{M} ; \quad\left[\mathrm{K}_{2} \mathrm{~S}_{2} \mathrm{O}_{8}\right]=0.03 \mathrm{M} ;$ $[\mathrm{Fe}(\mathrm{III})]=1.5 \times 10^{-3} \mathrm{M}$ at $50^{\circ} \mathrm{C}$ for $6 \mathrm{~h}$; standard $=66.6 \%$.

$2.5 \%$ onwards. The enhancement of graft percentage with formic acid and acetic acid at the cited compositions may be due to (i) acetic acid radical $\left(\dot{\mathrm{C}} \mathrm{H}_{2}-\mathrm{COOH}\right)$ contributing towards generation of greater number of grafting sites on the jute backbone and (ii) swelling of the fibers in the presence of formic acid may permit the monomer and the initiator to diffuse into the fiber matrix. Then, grafting is initiated both at and below the fiber surface. In addition the swelling of the fibers also permits high accessability of the surface of the jute fibers towards attack by primary radicals, creating more number of free radical sites leading to graft initiation. The retardation of the rate at higher percentage of acetic acid and formic acid $(>5 \%)$ and with rest of the solvents may be due to (i) the chain transfer ability of these solvents leading to premature termination of the growing grafted chains, (ii) massive formation of homopolymers by excess of the solvent radicals upsets grafting, (iii) shielding of the jute radicals by solvent cage arising from interchain hydrogen bonding of the solvent molecules as a result of which monomer addition onto the grafting sites is restricted. This is in alliance with the view of Kern and coworker ${ }^{46}$ and Palit and coworkers. ${ }^{47}$ 
Table III. Effects of graft percent on tensile properties of PMAM grafted jute fibers

\begin{tabular}{|c|c|c|c|c|}
\hline \multirow[t]{2}{*}{ Samples } & \multirow[t]{2}{*}{$\begin{array}{l}\text { Graft- } \\
\text { ing } \\
\%\end{array}$} & $\begin{array}{c}\text { Elongation } \\
\text { at break } \\
\text { B.L. }\end{array}$ & \multirow[t]{2}{*}{$\frac{\text { Tenacity }}{\text { g/denier }}$} & \multirow[t]{2}{*}{$\begin{array}{c}\text { Tensile } \\
\text { modulus } \\
\text { at break }\end{array}$} \\
\hline & & $\%$ & & \\
\hline Jute & 0 & 0.9 & 1.0 & 110.9 \\
\hline Jute-g-PMAM & 14.8 & 1.3 & 1.5 & 117.2 \\
\hline Jute- $g$-PMAM & 44.4 & 1.3 & 1.9 & 146.1 \\
\hline Jute-g-PMAM & 60.4 & 1.4 & 2.2 & 155.7 \\
\hline Jute- $g$-PMAM & 70.6 & 1.5 & 2.4 & 161.3 \\
\hline
\end{tabular}

\section{Properties of the Graft Copolymers}

Methyl acrylamide grafted jute fibers have the following properties.

(a) the absorption of water and water vapors increases.

(b) the lustre of the fiber increases.

(c) resistance towards the attack of mineral acid and alkali increases.

(i) Tensile Properties. The tensile properties of the parent and grafted jute fibers were evaluated with tenacity ( $\mathrm{g} /$ denier) and elongation at break, following the methods of Huque et al. $^{4}$ and Samal et al. $^{37}$ After conditioning the samples, they were combed and fiber aggregates of uniform length. The tenacity of the weighed samples was determined using Zwelgies strength tester. The tensile modulus at break was determined from the relationship:

Tensile modulus at break

$$
=\frac{\text { Tenacity at break }}{\text { Elongation at break }}
$$

The tensile modulus at break can also be determined from the slope of the stress-strain curve. In both methods, the same value of tensile modulus is obtained as seen in Table III. Grafting of MAM onto jute fibers increases its elongation at break, tenacity and the tensile modulus which increases with increase of graft percent. The enhancement in tensile properties of the grafts may be attrib-

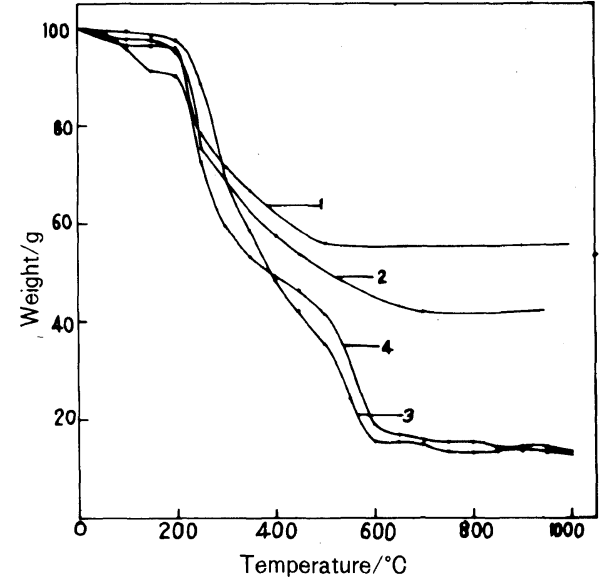

Figure 3. Primary thermograms of parent jute and jute grafted with methyl acrylamide: Sample No. 1, 0.0 (parent jute); No. 2, 44.4 graft $\%$; No. 3, 60.4 graft $\%$; No. 4, 70.6 graft $\%$.

uted to the internal cross-linking of the fiber backbone through bimolecular termination of. growing grafted chains and this imparts elastic nature to the fibers which increases with increase of graft percent.

(a) Thermogravimetric Analysis (TGA). The TGA curves (Primary thermograms) for the parent jute and PMAM-grafted jute, with different percent grafting $(44.4-70.6 \%)$ are shown in Figure 3. The parent jute undergoes nearly $45 \%$ weight loss between $200-500^{\circ} \mathrm{C}$. This may be due to the amorphous region in the fibers and partly due to the presence of lignin component. On the other hand, jute grafted with MAM shows peculiar behavior. The grafts undergo progressive weight loss upto $650^{\circ} \mathrm{C}$, with major weight loss of $58 \%$, $83 \%$, and $85 \%$ for the sample of percent grafting of $44.4,60.4$, and 70.6 , respectively. Further beyond $200^{\circ} \mathrm{C}$ the grafts undergo earlier decomposition, than the ungrafted fibers. This may be due to earlier decomposition of PMAM grafted chains on the backbone of the jute fibers. Continuous depletion of the primary thermograms of the grafts upto $650^{\circ} \mathrm{C}$ indicates that grafting takes place more into the amorphous region of the fiber. This seems 
Table IV. $n$ and $E$ Values of parent jute and jute- $g$ PMAM graft copolymers of various graft percent

\begin{tabular}{lccc}
\hline \multicolumn{1}{c}{ Samples } & $\begin{array}{c}\text { Grafting } \\
\%\end{array}$ & \multicolumn{1}{c}{$E$} & \\
\cline { 3 - 3 } & & $\mathrm{kcal} \mathrm{mol}^{-1}$ & \\
\hline Parent jute & 0.0 & 17.6 & 1.5 \\
Jute- $g$-PMAM & 44.4 & 24.5 & 1.0 \\
Jute- $g$-PMAM & 60.4 & 36.6 & 1.2 \\
Jute- $g$-PMAM & 70.6 & 27.8 & 1.0 \\
\hline
\end{tabular}

to be true, as the fiber grafted with PMAM upto $44.4 \%$ had primary thermograms pattern similar to the virgin jute fibers even though the former suffers weight loss upto $58 \%$ between $200-650^{\circ} \mathrm{C}$. From the primary thermogram in Figure 3 the values of $W, 1 / T$ and $\mathrm{d} w / \mathrm{d} t$ were calculated. Further plots of $\mathrm{d} w / \mathrm{d} t v s .1 / T$ and $W v s .1 / T$ yielded a pair of curves for each primary thermogram. From these curves the values of $\Delta \log (\mathrm{d} w / \mathrm{d} t)$ and $\Delta \log W$ at equally spaced interval of $1 / T$ were calculated. From values of $\Delta \log (\mathrm{d} w / \mathrm{d} t)$ and $\Delta \log W$, the Freeman and Carroll equation ${ }^{48,49}$

$$
\left(\begin{array}{c}
\Delta \log \frac{\mathrm{d} w}{\mathrm{~d} t} \\
\operatorname{or} \\
\Delta \log R_{\mathrm{T}}
\end{array}\right)=n \Delta \log W-\frac{E}{(2.303 R)} \Delta\left(\frac{1}{T}\right)
$$

was plotted. Data laid on straight lines, from the slopes and intercepts of which the order of the pyrolysis $n$ and the activation energy $E$ involved in the pyrolysis can be evaluated. The values of $n$ and $E$ are presented in Table IV.

The $n$ values in Table IV indicate that for the grafted samples the decomposition follows a simple first order path where as the value of $n$ for the parent fiber indicates the course of decomposition to be complex as has been indicated from the asymptotic nature of the pyrolysis curve beyond $500^{\circ} \mathrm{C}$ after which the fiber charred to black mass. The activation energy values in Table IV indicate that grafting of MMA onto the fiber increases its thermal stability beyond $500^{\circ} \mathrm{C}$ which increases with increase of graft percent upto 60.4. The decrease in activation energy for the sample with higher percent grafting (70.6) may be attributed to the involvement of more number of grafted chains in the pyrolysis, as a result of which the graft copolymer $(70.6 \%$ grafting) somewhat behaves as a composite of jute with poly(methyl methacrylate).

Acknowledgements. The authors are highly thankful to Prof. Y. Ikada, Research Centre for Medical Polymers and Biomaterials, Kyoto University, Japan, for his continuous inspiration and valuable suggestions. The financial support U.G.C., India, New Delhi is greately acknowledged.

\section{REFERENCES}

1. S. N. Ushakov, Fiz-Mat. Nauk, 1, 33 (1946).

2. Arthur D. Little, "The Engineering Properties of Fibers," Incorporated Cambridge, Massachusetts, 1966.

3. I. M. Trivedy and P. C. Mehta, Cellulose Chem. Technol., 7, 401 (1973).

4. M. M. Haque and M. D. Habibuddowla, Bangladesh J. Sci. Ind. Res., 15(1-4), 64 (1980).

5. M. D. Habibuddowla, "American Chemical Society Symposium Series," Vol. 187, D. N. S. Hon, Ed., 1982, pp 73-82.

6. P. Ghosh, A. R. Bondapadhya, and S. Dash, J. Macromol. Sci. Chem., A19, 1165 (1983).

7. P. Ghosh and S. K. Paul, J. Macromol. Sci. Chem., A20, 169 (1983).

8. F. R. Siddiuque, A. U. Khan, and R. A. Sheikh, J. Bangaladesh, Acad. Sci., 7(1-2), 87 (1983).

9. S. Jena, Ph. D. Thesis, Utkal University, India (1984).

10. S. S. Tripathy, Ph. D. Thesis, Utkal University, India (1984).

11. A. Hebeish, A. Hizzy, and N. Y. Aboe-Zeid, Angew. Macromol. Chem., 121, 69 (1984).

12. B. C. Singh, A. K. Mohanty, and M. Mishra, Angew. Macromol. Chem., 147, 185 (1987).

13. B. S. Singh, A. K. Mohanty, and M. Mishra, J. Appl. Polym. Sci., 33, 2809 (1987).

14. B. C. Singh and A. K. Mohanty, J. Appl. Polym. Sci., 34, 1325 (1987).

15. R. G. R. Bacon, Trans. Faraday Soc., 42, 140 (1946).

16. W. J. R. Evans, Trans. Faraday Soc., 42, 155, 668 (1946).

17. L. B. Morgan, Trans. Faraday Soc., 42, 169 (1946). 
18. I. M. Kolthoff, A. I. Medalia, and H. P. Rain, J. Am. Chem. Soc., 73, 1733 (1951).

19. H. W. Starkweather, Ind. Eng. Chem., 39, 210 (1947).

20. C. S. Marvel, J. Polym. Sci., 3, 181 (1948).

21. P. Ray and K. Chakrabarty; J. Indian Chem. Soc., 21, 47 (1947).

22. R. W. Rainward, J. Polym. Sci., 2, 16 (1947).

23. A. Y. Kulkarani, A. G. Chitale, B. K. Vaidya, and P. C. Mehta, J. Appl. Polym. Sci., 7, 1581 (1968).

24. L. Sakurada and Y. Sakaguchi, Sen'i Gakkaishi, 19, 217 (1963).

25. S. Obuchi, I. Yoshitake, T. Tsuneda, and H. Maeda, Sen'i Gakkaishi, 20, 162 (1964) [Chem. Abstr., 63, 780 (1965)].

26. M. Mukhopadhyaya, J. Prasad, and S. R. Chatterjee, Makromol. Chem., 176, 1 (1975).

27. K. Bardhan, S. Mukhopadhyaya, and S. R. Chatterjee, J. Polym. Sci., Polym. Chem. Ed., 15, 141 (1977).

28. N. G. Gaylord and T. Tomono, J. Polym. Sci., Polym. Lett. Ed., 13, 698 (1975).

29. T. Shiru, T. Akira, and T. Akira, Kogakuin Daigaku Kenkyu Hokoku, 43, 232 (1977).

30. V. N. Kislenko, A. A. Berlin, and B. L. Chernyak, Zh. Priki. Khim. (Leningrad), 53, 617 (1980).

31. D. Donescu, I. Deaconescu, K. Gosa, M. Mazare, and I. Gavat, Rev. Roum. Chim., 25, 975 (1980).

32. G. I. Titledman, V. A. Volkov, A. A. Pantilov, and E. N. Zilberman, Izv. Vyssh. Uchebn. Zaved, Khim. Khim. Tekhnol., 25, 1258 (1982).

33. R. K. Samal, P. K. Sahoo, and H. S. Samantaray, J. Mol. Sci-Rev., Macromol. Chem. Phys. C, 26, 81 (1986).
34. D. R. Burfied and S. C. Nag, Eur. Polym. J., 12, 873 (1976).

35. N. G. Gaylord, J. Polym. Sci., C, 37, 153 (1972).

36. A. Hebeish, M. I. Khalil, and M. H. El-Rafie, Angew. Makromol. Chem., 37, 149 (1979).

37. R. K. Samal, H. S. Samantaray, and R. N. Samal, Polym. J., 18, 471 (1986).

38. K. S. V. Srinivasan, M. Santappa, and D. N. S. Hon, "American Chemical Society Symposium Series," Vol. 187, D. N. S. Hon, Ed., 1982, pp 155-178.

39. Z. A. Rogovin and B. P. Morin, Polym. Sci., USSR, $A, 18,2451$ (1976).

40. B. N. Mishra, R. Dogra, J. Kaur, and J. K. Jassal, J. Polym. Sci., Polym. Chem. Ed., 17, 1861 (1979).

41. R. K. Samal, M. C. Nayak, and P. L. Nayak, Angew. Makromol. Chem., 80, 95 (1979).

42. R. K. Samal, S. C. Satrusallya, B. L. Nayak, and C. N. Nanda, J. Appl. Polym. Sci., 28, 1311 (1983).

43. R. K. Samal, P. K. Sahoo, and H. S. Samantaray, J. Appl. Polym. Sci., 32, 5693 (1986).

44. C. H. Bamford, A. D. Jenkins, and R. Johnston, Proc. R. Soc., Ser. A, 239, 241 (1957).

45. R. K. Samal, T. R. Mohanty, and P. L. Nayak, Macromolecules, 10, 489 (1977).

46. W. Kern, R. Schulz, G. Renner, and A. Henglein, Makromol. Chem., 12, 20 (1954).

47. S. R. Palit and R. S. Konar, J. Ind. Chem. Soc., 38, 481 (1961).

48. D. A. Anderson and E. S. Freeman, J. Polym. Sci., 54, 253 (1961).

49. E. S. Freeman and B. Carrol, J. Phys. Chem., 62, 394 (1958). 